\title{
Pluralism as Multi-Method Scholarship in Qualitative Social Science Research: A Panacea for Methodological Tribalism
}

\author{
Dr. M.N. Mohamedunni Alias Musthafa \\ Assistant Professor (on Deputation: Reader, UGC-Academic Staff College, University of Calicut), Department \\ of Education, University of Calicut, Thenjipalam, Malappuram, Kerala- 673635
}

\begin{abstract}
Over the years the research endeavours in social sciences have been directed towards producing profound discoveries about humankind and the society they live in. Now-a-days qualitative research has been flourishing in many fields of the social sciences. Rapid social change and the resulting diversification of life scenarios are increasingly confronting social researchers with new social contexts and perspectives. There is a specific relevance for qualitative research to the study of social contexts and life situations. This has lead to the development of several social theories and social research methods which have still continued to develop in order to understand the diverse social problems. The challenge for social scientists and researchers worldwide is to continue in the search for a unified consensus on what methodology is to be adopted for research for meeting the emerging diverse needs of humankind and the society. This thought has led to the proliferation of pluralism or multi-method research in which the researcher synthesizes multiple research methodologies in order to study social problems in a holistic way. This concept of pluralism in research has to a greater extend subverted methodological tribalism which had existed till the recent past. This paper focuses on the philosophical assumptions as guidelines to research paradigms have influenced the development of social research theory and social research methods towards pluralism. This paper intends to explore pluralism in qualitative Social Science researches as it may be applied methodologically and philosophically. In this context, the paper heeds a thought on refocusing pluralistic qualitative research in terms of its needs and demands based on the level and depth of the study undertaken.
\end{abstract}

Key Terms: Qualitative research, methodological pluralism, research paradigms, philosophical assumptions

\section{Introduction}

The world today is witnessing a proliferation of social science research. Dynamism and complexity in social science researches have contributed to attracting much attention in the research arena (Dube and Pare, 2003). As modern societies become more complex in their structure, needs and demands, social problems have also become more and more complex. This has lead to the development of several social theories and social research methods which have still continued to develop in order to understand the diverse social problems.

Presently social research is in its glorious path of rapid change and development. The challenge for social scientists and researchers worldwide is to continue in the search for a unified consensus on what methodology to be adopted for research for meeting the emerging diverse needs of humankind and the society. This methodology should be powerful as well as refined so as to connect a proposed 'grand theory' with the various midrange theories with considerable success. This in turn should be able to provide usable frameworks for increasing the overall knowledge of society. Due to this quest, the social science research is experiencing a paradigm shift that calls for the re-examination of current methodologies. This is important as it will successfully contribute in the orientation of social science researchers of all generations to be innovative and go beyond conventional boundaries. This thought has led to the proliferation of pluralism or multi-method research in which the researcher synthesizes multiple research methodologies in order to study social problems in a holistic way. This concept of pluralism in research has to a greater extend subverted methodological tribalism which had existed till the recent past.

Pluralism has become increasingly prominent in a variety of disciplines and fields like management studies, education, psychology, sociology and clinical fields. The multi method research is often considered as simple, but powerful on the grounds that if various methods used by the researcher have weaknesses that are different, then their amalgamated findings can be accepted with far greater confidence than any single method's findings would demand. This paper focuses on the philosophical assumptions as guidelines to research paradigms have influenced the development of social research theory and social research methods towards pluralism. An attempt has been made to explore pluralism in qualitative Social Science researches as it may be applied methodologically and philosophically. In this context, the paper heeds a thought on refocusing pluralistic qualitative research in terms of its needs and demands based on the level and depth of the study undertaken. 


\section{An Overview Of Social Science Research}

Social Sciences are not exact sciences like physical sciences. It deals with human beings who form a part and parcel of the society. Human nature and the environment they live in are so complex and dynamic that it is more difficult to comprehend and predict human behaviour than physical phenomena. The human behavioural influences may be attributed to biological, psychological, socio-cultural, temporal and environmental factors. Hence it is often difficult to understand and study the underlying uniformities in the diversity of complex human behaviour.

Literature defines social research as research conducted by social scientists (Ragin, 1994; Firebaugh, 2008). To be more precise, social science research examines a society's attitudes, assumptions, stratifications, rules, beliefs, trends and such related social orders in a social setting. Social research determines the relationship between one or more variables which is interdisciplinary study crossing into subjects like criminology, politics, economics, business, psychology, philosophy and anthropology.

Thus, Social Science research is a scientific study of society that is directed towards exploring, analysing and conceptualising human life intended to extend, correct or verify knowledge of human behaviour in a society. Social research thus attempts to create or validate theories through data collection and analysis with a goal directed towards exploration, description and explanation of unexplained social phenomena thereby clarifying doubts and correcting the misconceptions of social life. Social research seeks to find social patterns of regularity in social life and usually deals with social groups rather than individuals themselves.

\section{Philosophical Assumptions In Social Science Research}

The philosophy of social sciences aims at producing rational reconstruction (descriptive) as well as seeks to critique social sciences with an intention to explain the social world for better understandings (prescriptive). In any discipline, there will always be a number of underlying philosophical predispositions in the works of scientists involving the nature of social knowledge, the nature of social reality and the locus of control of the individual in action.

Thus, the philosophy of social science is both descriptive and prescriptive. It is concerned with a number of interrelated questions. These include: What is the method(s) of social sciences? Do social sciences use the same methods as natural sciences? If not, should it follow the same methods? Are the methods appropriate to conducting a social inquiry fundamentally different from those of natural sciences? Are the scientific investigations of the social world even possible or even desirable? What is the type of knowledge that the social inquiry produces? Can the social sciences be objective and value free? Is there a need to strive for it? Does the social world represent a unique realm of inquiry with its own properties and laws? And can the regularities and other properties of the social world be reduced to facts about individuals? Differences in researchers' answers to these questions have led to the divergent 'schools', 'interpretive frameworks' and approaches to qualitative research. The three philosophical assumptions that are predominant in influencing social researches are ontology, epistemology and methodology. The following section gives a brief overview of this.

\section{Ontological Assumptions Of Social Science Research}

Ontology signifies the nature of reality and what there is to know about the world. Key ontological questions concern whether social reality exists or not and if it exists, whether it exists independently of human conceptions and interpretations. It is also concerned with whether there is a shared social reality or only multiple, context-specific ones. In very broad terms, social science has been shaped by two cardinal ontological positions like realism and idealism.

Realism is based on the idea that there is an external reality which exists independently of people's beliefs or understandings of it. That is, there is a distinction between the reality about the world and the meaning and interpretation of that world held by individuals. On the other hand, idealism asserts that reality is fundamentally mind-dependent. That is, it can only be known through human mind and through socially constructed meanings. This implies that no reality exists independently of these philosophical positions and also, it is able to identify a number of more differentiated perspectives.

\section{Ontological Positions}

There are several ontological positions taken by the researchers that depict the nature of the world and what there is to know about it involving realism and idealism. Variants of realism include naive realism (Madill et al., 2000), or shallow realism (Blaikie, 2007) in which the reality can be observed directly and accurately. Whereas under cautious realism (Blaikie, 2007) reality can be known approximately or imperfectly rather than accurately. Under depth realism (Blaikie, 2007), critical or transcendental realism (Bhaskar, 1978) reality consists of different levels like, the empirical domain that is made of up what we experience through our senses, the actual domain that exists regardless of whether or not it is observed, and the real domain that refers to 
underlying processes and mechanisms. Under subtle realism (Blaikie, 2007) an external reality exists but is only known through the human mind and socially constructed meanings. Materialism is a variant of realism which recognises only material features like economic relations or physical features of the world as holding reality. Values, beliefs or experiences are 'epiphenomena' which relates to features that arise from, but has no role in shaping the material world.

Under Idealism no external reality exists independent of our beliefs and understandings. It includes subtle or contextual or collective idealism (Hughes and Sharrock, 1997; Madill et al., 2000) in which the social world is made up of representations constructed and shared by people in particular contexts. Under relativism or radical idealism (Hughes and Sharrock, 1997; Madill et al., 2000) there is no shared social reality, only a series of different (individual) constructions.

\section{Key Issues Dominating Ontological Debates in Social Science Research}

An underlying ontological question is concerned with whether the social and natural worlds exist in similar ways or whether the social world is fundamentally different because it is open to subjective or individualistic interpretations. Some early conceptions that existed was that the social world was similar to the physical world and was governed by universal causal laws. However, it has been argued that the two are very different and that any regularities identified by social enquiry cannot be governed by immutable laws, because human beings have agency and therefore have choice about what they do (Hughes and Sharrock, 1997; Patton, 2002). Many contemporary qualitative researchers would share this latter view, rejecting the idea that fixed 'laws' governing the social world exist or could be identified.

\section{Epistemological Assumptions Of Social Science Research}

Epistemology is concerned with Knowledge and clarifies researcher's beliefs about how knowledge is created. It involves the different ways of knowing and learning about the world and focuses on issues such as how we can learn about reality and what forms the basis of our knowledge. There are two contrasting views like normative epistemology and interpretative epistemology. The normative view holds that research creates knowledge by building on the foundations of accepted and rationally defensible theory (positivism). The interpretative view is that research must set aside existing knowledge and discover new knowledge from internal coherence (constructivism).

Epistemology is viewed differently in different research paradigms. Epistemology in the positivist paradigm supports the idea that the social world can be investigated through natural science methodologies. Hypotheses have to be tested by empirical approaches. Data need to be objectively analysed through scientific methods. Contrastingly, epistemology in the constructivist paradigm supports the idea that knowledge can be acquired by investigating the phenomena in many ways because the social context is different from natural science.

\section{Epistemological Positions}

There are several epistemological positions taken by the researchers that depict how we can know or find out about the social world and the limits to that knowledge. It includes the inductive logic that involves building knowledge from the bottom up through observations of the world which in turn provide the basis for developing theories or laws. On the other hand there is also the deductive logic, which is a top-down approach to knowledge. It starts with a theory from which a hypothesis is derived and applied to observations about the world. The hypothesis will then be confirmed or rejected, thereby strengthening or weakening the theory.

Blaikie (2007) has suggested two further logics of enquiry into the social world which includes the retroductive logic that involves the researcher identifying the structures or mechanisms that may have produced patterns in the data, trying different models for 'fit'. The other one being the abductive logic that involves 'abducting' which is a technical account utilizing the researchers' categories from participants' own accounts of daily activities, beliefs or ideas.

Other epistemological concepts or positions relevant to qualitative research focus on the nature of knowledge or truth, like the foundational and fallibilistic models of research based knowledge. While a foundational model of research-based knowledge assumes that it is possible to reflect 'reality' exactly, a fallibilistic model treats all knowledge claims as provisional. Then there is the knowledge as 'value-mediated' that holds that all knowledge is affected by the values of the person who produces/receives it. While in the correspondence theory of truth, a statement is true if it matches independent reality, the coherence theory of truth an account is true as a representation of the (socially constructed) world if it is supported by several other accounts if different accounts 'cohere' with each other. Under the pragmatic theory of truth beliefs are true if they have practical utility ie., if believing them is useful, helpful and productive to people. 


\section{Key Issues Dominating Epistemological Debates in Social Science Research}

Several key issues dominate epistemological debates in social science researches. The first one is related to the way in which knowledge is best acquired. One view holds that knowledge is based on induction, a 'bottom-up' process through which general patterns are derived from specific observations of the world. On the contrary, those who argue that knowledge is acquired through deduction, views knowledge acquisition as a 'topdown' process whereby logically derived propositions or hypotheses are tested against observations. That is to say, inductive processes involve using evidence as the genesis of a conclusion where in evidence is collected first based on which knowledge and theories are built. Deductive processes use evidence in support of a conclusion wherein a hypothesis is first developed and evidence is then collected to confirm or reject it.

Quantitative research is often depicted as deductive process and qualitative research as an inductive process. However, Blaikie (2007) argues that there is no such thing as 'pure' induction or 'pure' deduction. For example, when so-called inductive researchers generate and interpret their data, they cannot approach this with a blank mind. This implies that even if they are not testing a hypothesis, the data, the questions and the analytical categories employed, probably would have been influenced by assumptions deductively derived from previous work in their field. In the same way, deductive researchers setting out to test a hypothesis would have drawn on a body of theory which in turn has been inductively derived from previous observations.

The second important epistemological issue within social research is concerned with the relationship between the researcher and the researched and the way this influences the connection between 'facts' and 'values'. In one model, the phenomena being researched are seen as independent of and unaffected by the behaviour of the researcher thereby being 'objective' in their approach and the investigation can be viewed as 'value free'. When some researchers follow this model, there are others who believe that in the social world people are affected by the process of being studied and that the relationship between the researcher and social phenomena is interactive. Under such circumstances, the researcher cannot be neutral and cannot produce an objective or value free result. Findings are thus either mediated through the researcher ('value mediated'), or are negotiated and agreed between the researcher and research participants. Between value free (objective) observation and value-mediated observation, some researchers propose 'empathic neutrality'. This position recognises that research cannot be value free, but advocates that researchers should try to make their assumptions, biases and values transparent. At the same time they should be striving as far as possible to be neutral and non-judgemental in their approaches of research. In this context, reflexivity in qualitative research is considered as particularly important for deriving valuable conclusions.

The third epistemological issue relating to social science research focuses on what it means to accept particular claims as accurate or 'true'. In the natural sciences, the 'dominant theory of truth' has been held to be one of correspondence. Here the researcher looks for a match between observations or readings of the natural world and an independent reality. An alternative view is the inter-subjective or 'coherence theory of truth' which suggests that this 'independent' reality can only be gauged in a consensual rather than an absolute way. This is proposed as more appropriate for the study of the social world. Under this, if several reports confirm a statement then it can be considered 'true' as a representation of a socially constructed reality. Lastly there are those who argue for a 'pragmatic theory of truth' which holds the premise that an interpretation is true if it leads to or provides opportunities to take actions that produce the desired or predicted results in the research pursued.

\section{Methodological Assumptions Of Social Science Research}

Methodological assumptions focuses on analysis of the methods used for gathering research data. In positivist paradigm, the scientific method (quantitative) is used to observe the phenomena under study. It uses numerical calculations to generalize the finding and test the theory. On the other hand, the constructivist paradigm uses qualitative methods like observations, fieldwork notes, interviews, etc to investigate the phenomena of research.

\section{Key Issues Dominating Methodological Debates in Social Science Research}

One of the major challenges social researchers encounter is the negative perception that social research is not considered as scientific as natural sciences. During the $19^{\text {th }}$ century studies related to societies were not considered as scientific in the true sense of the word. However, several studies and situations along with the clarifications of social scientists and experts, today social research is considered as scientific in every aspect.

As a matter of fact, contemporary intellectuals have often disagreed about the extent to which the social sciences should mimic the methods used in the natural sciences. The founding positivists of the social sciences (Kember \& Dekers, 1987; Osman \& Wagner, 1987) have argued that social phenomena can and should be studied through conventional scientific methods. On the other hand, proponents of social sciences (Campbell and Stanley 1963; Cook and Campbell, 1979) supported the idea that there is a need for an interpretive approach to the study of human behaviour, a technique that is radically different from the natural sciences. 
Thus, the fundamental task for the philosophy of social sciences has been to question the extent to which social research may be characterized as 'scientific' in relation to fundamental epistemological foundations. These debates rage within contemporary social sciences with regard to objectivity, subjectivity, inter-subjectivity, role of the social science researcher, the complexity of the matter, and practicality in the conduct of social research.

Nevertheless the qualitative researcher does not stand outside or above the study, rather is situated within the very processes being studied (Denzin, 2001). Despite the rigorous efforts and best intentions of the researcher, social science research reflects the values and viewpoints of the inquirer and is theory laden. In social science research one cannot escape the reality that the researcher is an instrument that filters data through own paradigms thereby bringing about subjectivity and the research intuitive and value laden. Thus, in reality, the social researcher actually forms a part of the study.

\section{Mechanistic Inter-Relationship Between The Building Blocks Of Research}

A mechanistic inter-relationship between ontology, epistemology, methodology, methods and sources has been presented by Grix (2004). In this, methodology translates the principles of a paradigm into a research language and depicts how the world can be explained, handled, approached or studied (Grix, 2004). Methods refer to the techniques or procedures used to generate and analyze data (Grix, 2004; Cohen, et al., 2007). Sources are the responses to the methods used in a study, which may be responses to a questionnaire or interview transcripts.

From the above discussion it seems that ontology is the starting point of research. It is the views about reality that defines the epistemological assumptions and the methods to be used in the study. For example, if we believe that reality is socially constructed by the people, then it is subjective and lies in peoples' minds and we are likely to adopt epistemological standpoint in line with our views of reality. As a researcher, we may be more inclined to use qualitative methodology in which the participants have a say in the process of data collection.

The Inter-relationship between the Building Blocks of Research

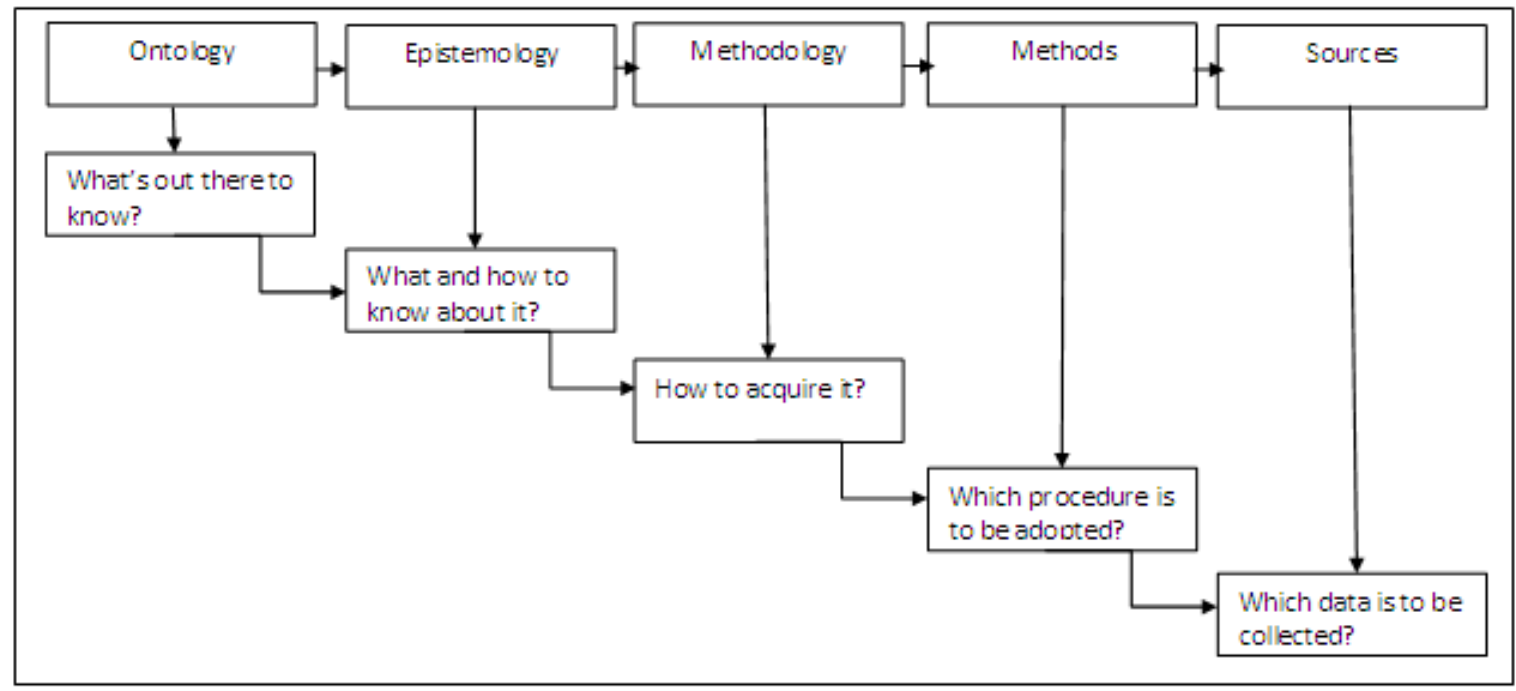

\section{The Research Paradigms}

Source: Grix(2004, p. 66)

The building blocks of research depicts that each paradigm of research has some distinct assumptions about the nature of reality and how it may be known and what types of methods may be used to find out the reality.

\section{The Research Paradigms In Social Sciences}

A research paradigm signifies the way of looking at the world. All research paradigms are based on the philosophical assumptions that guide and direct the thinking and action of a researcher. It usually comprises the researchers' ontology, epistemology, methodology and axiology. Researchers such as Lather (1992), Lincoln and Guba (2000) have identified three major paradigms that have influenced social research like Positivism, Constructivism, and Pragmatism. The present discussion focuses on how these three paradigms have influenced the development of social research theory and social research methods.

According to Guba (1978), most research work is guided by either positivism (quantitative) research paradigm or constructivism (qualitative) research paradigm or a mixture of the two paradigms (pragmatism). Each approach represents a fundamentally different inquiry and researcher actions are based on the underlying 
assumptions of each paradigm. The following section discusses the various paradigms of social science research like positivism, constructivism and pragmatism.

Positivism is commonly referred to as the quantitative paradigm and reflects the traditional scientific approach to problem solving. It is based on the rationalistic and empiricist philosophy that originated with the deductive approach of Aristotle, John Lock, August Compte, and Emmanuel Kant (Mertens, 2005). It is associated with 'scientism', the view that the methods of natural sciences may be applied to all areas of investigation, whether it is philosophical, social, scientific or otherwise. Positivism assumes that there is a method for studying the social world that is value free and that explanations of a causal nature can be provided. It also asserts that the events or observations are influenced by a single theory or paradigm.

Epistemologically, positivist studies are premised on the existence of a priori fixed relationships within phenomena capable of being identified and tested through hypothetic-deductive logic and analysis. The deductive method argues that knowledge must proceed from the general to the specific. Under this, researcher begins with a hypothesis followed by making observations or collecting data for hypothesis testing. Based on empirical evidence obtained, the researcher decides whether to accept or reject the hypothesis. Causal relationships, which are the basis for generalized knowledge, can predict patterns of behaviour across situations. Ontologically, positivist research assumes an objective physical and social world that exists independently of humans. The researcher is seen to play a passive, neutral role, and does not intervene in the phenomenon under study. Keeping in spirit with this set of beliefs, a theoretically grounded positivist study is likely to be conducted with the ideas of establishing appropriate measures (qualitative and/or quantitative) for the constructs being studied; establishing or testing causal relationships; determining the domain to which the study's findings can be generalized; and demonstrating that the inquiry is value free.

Under Positivism (Willis, 2007) or Empiricism (Blaikie, 2007), knowledge is produced through the senses based on careful observation wherein regularities and 'constant conjunctions' are identified. Inductive reasoning is used after data have been collected to generalise from empirical instances to general laws and reality is unaffected by the research process, facts and values are separate, objective value-free inquiry is possible. The methods used in the natural sciences are appropriate for studying the social world. Reality can be known accurately (knowledge is foundational, correspondence theory of truth).

Under Post-positivism, post-empiricism (Willis, 2007), falsificationism (Blaikie, 2007) knowledge of the world is produced through testing propositions: hypotheses about causal relationships are derived from scientific theories and then evaluated empirically against observations. Deductive reasoning is used to postulate possible relationships and models before data are collected and reality is unaffected by the research process, facts and values are separate, objective value-free inquiry is possible. The methods used in the natural sciences are appropriate for studying the social world. Reality can be known approximately whereby hypotheses can be rejected or provisionally accepted, but not definitively proved to be true. Here, knowledge is considered as provisional and fallibilistic.

Interpretivism gives emphasis on interpretation as well as observation in understanding the social world. It came as a reaction to positivism and has been seen as integral to qualitative research. The related movement of 'constructionism' emphasises that knowledge is actively 'constructed' by humans, rather than being passively received by them. Under interpretivism (Bryman, 1988; Holloway and Wheeler, 2010; Lincoln and Guba, 1985; Willis, 2007) or constructionism (Blaikie, 2007; Crotty, 1998), knowledge is produced by exploring and understanding the social world of the people being studied, with a focus on their meanings and interpretations. According to Cook and Campbell (1979), constructivist paradigm rejects the position that social events or observations are influenced by a single theory or paradigm.

The research process in an interpretivist paradigm is considered to be largely inductive in the sense that interpretation is grounded in the data, though it is also recognised that observations are 'theory laden' because they are mediated by ideas and assumptions. The proponents of interpretivist/constructionist paradigm criticized positivism for applying natural sciences on human beings. Their ontological views are different. This research paradigm proposes that reality is socially constructed and that it can be studied through the direct detailed observation of people in natural setting in order to arrive at understanding and interpretations of how people create and maintain their social worlds. Reality is affected by the research process, facts and values are not distinct, and objective value-free research is impossible. Some researchers may aim to be transparent about their assumptions and attempt to adopt a neutral position; others embrace subjectivity and become more personally engaged in the research.

In the real world, events cannot be teased out from the context in which they are inextricably embedded. Understanding of such events involves the relationships among all of the many parts of the whole. Smith and Manning (1982) suggest that qualitative research is better for initial exploratory research into unknown or unfamiliar phenomena. It helps the researcher to develop concepts, hypotheses, interpretations and theories empirically grounded in the investigated systems. Thus qualitative methods which emphasize both inner 
and outer knowledge of humans in their world, are preferable. Moreover qualitative method is preferred for researchers working in the constructivist paradigm.

Though the widespread adoption of qualitative methods across the social sciences is a relatively recent phenomenon, the early development of ideas now associated with qualitative research can be linked to the writing of Immanuel Kant, who published 'Critique of Pure Reason' during 1781. Kant argued that there are ways of knowing about the world other than direct observation and that people use these all the time. He proposed that perception relates not only to the senses but to human interpretations of what the senses tell us. Knowledge of the world is based on 'understanding', which arises from reflecting on what happens, not just from having had particular experiences. Following this line of reasoning in research, those practising qualitative research have tended to place emphasis and value on human interpretation of the social world and the significance of both participants' and the investigator's interpretations and understanding of the phenomenon being studied.

Another key contributor to the development of interpretivist thinking and the qualitative research tradition was Wilhelm Dilthey whose writing, during the 1860s and 70s, emphasised the importance of 'understanding' and of studying people's 'lived experiences' which occur within a particular historical and social context. An argumentation was also put forth by him that self-determination and human creativity play very important roles in guiding our actions. Therefore he proposed that social research should be directed towards exploring the actual experiences in order to reveal the connections between the social, the cultural and the historical aspects of people's lives and to see the context in which particular actions take place.

Pragmatism is a paradigm that provides the underlying philosophical framework for mixed methods research (Maxcy, 2003; Patton, 2002; Tashakkori and Teddlie, 2003). This research design involves methods that use mixed data (numbers and text) and additional means (statistical and textual analysis). A mixed method uses both deductive and inductive scientific methods and has multiple forms of data collecting and produces eclectic and pragmatic reports. Pragmatic philosophers (Maxcy, 2003; Patton, 2002; Tashakkori and Teddlie, 2003) have rejected the scientific notion that social science enquiry was able to access the truth about the real world solely by virtue of a single scientific method. Towards th this, the most appropriate paradigm is the mixed research approach in which the researcher is not confined to one research method.

Under pragmatic paradigm a mixed research design is generally adopted that includes quantitative and qualitative research data, techniques and methods. According to Mertens (2005) mixed methods can be applied at four different levels like identification of the problem, data collection, data analysis and discussion of research findings. Some authors argue that Caracelli and Greene (2002) are that social researchers mix methods to a varying degree at various points in their research and still call their work mixed method research.

\section{Deploying Pluralism For Confronting Methodological Tribalism In Social Science Research}

The discussions of paradigms and quantitative and qualitative approaches presented a background and comparison to discuss methodological pluralism or mixed methods research. The simple idea that multiple methods may be deployed simultaneously in a single study, and also that such a study would be less prone to errors thereby being superior to researches employing a single method, has its origins in the behavioural revolution of the 1950s. Pluralism or methodological pragmatism presumes openness to a variety of methods, which should not be confounded with methodological relativism which presumes that everything works out rightly enough.

A pluralistic or mixed research complements a result from one type of research with another one without missing any available data. The quantitative component of a mixed research assumes the usage of deductive scientific method while qualitative component assumes inductive scientific method. Also, a quantitative approach collects quantitative data based on exact measurement applying structured as well as validated information collection, like rating scales, closed ended items and responses. This approach produces statistical reports with correlations. A qualitative component uses qualitative information from interviews, field notes, open ended questions etc. it considers a researcher to be the major means of information collection. Towards the end of research, this approach supposes a narrative report with context description with quotations taken from research material. Ultimately, the aim of a mixed method design is to summarize positive aspects of two approaches and produce a highly accurate data.

The ascendance of methodological pluralism is an evidence of the efforts of coming out against methodological tribalism. This is due to the general view that the future development of the field depends on continuous engagement, but in a way that moves conversations forward. Several social science researches advocates a pluralistic and pragmatic position, reaffirming that the selection of methodological approaches should depend on the questions being pursued, to be assessed one by one in detail. Different methods shine under different lights. Nevertheless it may have different limitations like depth versus breath, singularity versus generalisability, site based study versus drawing on a wider range of respondents and so on. 


\section{Towards A Pluralistic Paradigm In Qualitative Researches In Social Sciences}

Methodological pluralism is an emerging promising research paradigm prevailing in qualitative researches in Social Sciences. It is also referred to as mixed method research in which different methods and techniques are employed to explore, elaborate or explain different angles of the same phenomena. Methodological pluralism is considered as an appropriate basis for the study of human behaviour and experience (Davis, 2009). Being open to the full range of human experience, combining qualitative and quantitative methods provides a more balanced perspective, moving toward holism. Methodological pluralism can be used to understand the different aspect of the social phenomena and to get a candid description of the social world.

The use of both quantitative and qualitative methods is considered as a way to best understand research problems. However, pluralism must occur in an integrative way in a research (Barker, 2005). While synthesising methods, integration of different methods is most important in pluralistic research. Creswall et al., (2003) defines integration as the 'combination of quantitative and qualitative research within a given stage of inquiry'. As a matter of fact, the methods need to be integrated from the beginning of the research toward the process of data collection and analysis (Coxon 2005). The researcher also needs to be cautious while considering the pragmatic and epistemological implications of how those methods are to be brought into relationship with each other in a particular study.

According to Shih (1998), combining research methods is important to increase the validity of data thereby making the research useful and worthwhile. Mixed method approaches might be used to enrich or populate data in order to find a way to triangulate findings or to conduct a pilot study in order to inform a largescale quantitatively orientated project (Todd et al., 2004). Several developments in approaches to research have arisen from the application of mixed method approaches. These include pragmatism, bricolage and multi perspectival analysis. All seek to access as much meaning as possible from data but are applied in slightly different ways depending on the research questions and rationale for the research.

\section{Arguments Against Methodological Pluralism In Qualitative Researches}

The mixed method study is defined as the collection or analysis of both quantitative and/or qualitative data in a single study in which the data are collected concurrently or sequentially are given a priority and involve the integration of the data at one or more stages in the process of research (Creswell, 2013). This definition focuses two major points like collection and/or analysis of quantitative and qualitative methods and the integration of the data which is most important in mixed method researches. Quantitative and qualitative findings are either not integrated or integrated to only a limited extent. It is this lack of integration in mixed research that forms a major hindrance in the development of mixed methods research (Bryman, 2007).

The mixed research method has limited scope if the inter-relationship between ontology, epistemology and methodology is considered to be rigid and rigorous. Greene and McClintock (1985) suggests that 'any effort to compare or integrate findings from different methods requires the prior adoption of one paradigm or the other, even when the methods themselves are linked to and implemented within alternative paradigms'.

Similarly, Bednarz (1985: PP. 289-90) argues that there is reason to believe that qualitative and quantitative approaches cannot be synthesized because they occupy philosophical spaces that are alternative rather than complementary. It is necessary that any synthesis must adopt the perspective of one or the other in order that any effort to reach a middle ground does so only in terms of a single perspective.' Bednarz (1985: P. 304) asserts that cross philosophy triangulation is not possible because of the necessity of subsuming one approach to another. Nor can the researcher pick one aspect of an approach and one from another without making explicitly or implicitly commitments regarding these matters'. According to Silverman (1993) quantitative and qualitative methodologies are distinct and incompatible.

The main argument in the above cited literature is that quantitative and qualitative methodologies are opposite to each other and both are based on contradictory paradigms. Their views about reality, methodology, human beings and the purpose of research are different. It is most likely that the researcher will be a member of one academic community at a time. What if the researcher believes that reality is socially constructed, then how can the researcher believe at the same time that it is objective and 'out there' to know? Hence, the integration of methods from two competing approaches does not seem to be a reasonable idea. However, more than one methods of the same approach or same paradigm may be used in a single study.

Thus, the arguments for and against mixed methods indicate that the problem is not in the use of mixed methods, but how they are used in a study. Several criticisms raised by various writers are primarily based on the assumption that it is not reasonable to integrate two competing methods or paradigms. According to their view there is no problem, however, if methods are not contradictory to the ontological position. But what if two competing methods are used in the same study if they enhance understanding of the phenomenon? The following sections discusses about the different methods of implementing pluralism in qualitative social science researches. 


\section{The Multi Facets Of Pluralism: Synthesising Of Research Methodologies}

Pluralism, mixed method or multi method research can take several forms, reflecting the many possible permutations of methods drawn from the broad categories of qualitative, quantitative, and formal approaches. Two main types of a mixed method paradigms include the 'mixed research method' and 'mixed model designs'. In a mixed research method research the researcher uses quantitative data for one stage of a research study and qualitative data for a second stage of a research. In a mixed model design research the researcher use both quantitative and qualitative data in one or two stages of the research process. The synthesis or mixing of quantitative and qualitative approaches may happen in every stage of the research.

Methodological pluralism can combine discrete techniques within one of these families of methods. For example, when a study employs two formal models predicated on fundamentally different assumptions and parameters. Similarly, given the wide range of approaches labelled 'qualitative' a multi method approach can feature two or more types of qualitative analysis. On a larger scale, it is possible to imagine pluralism that incorporates models or techniques from different disciplines. The most common multi-method designs in the social sciences tend to combine some type of qualitative research with quantitative analysis or a formal model. Thus, methodological pluralism can be productively used in understanding people's experiences about abstract phenomenon. It may be used in a variety of contexts and in a variety of disciplines.

\section{Strengths And Weaknesses Of Pluralistic Or Mixed Method Researches}

Some of the merits and demerits of pluralistic/ mixed method researches as put forth by Johnson and Onwuegbuzie (2004) are presented below:

\section{Strengths of Mixed Method Researches}

- Words, pictures, and narrative can be used to add meaning to numbers and vice versa.

- Provides quantitative and qualitative research strengths.

- Researcher can generate and test a grounded theory.

- Answers a broader and more complete range of research questions because the researcher is not confined to a single method or approach.

- A researcher can use the strengths of an additional method to overcome the weaknesses in another method by using both in a research study.

- Provides stronger evidence for a conclusion through convergence and corroboration of findings.

- Add insights and understandings that might be missed when only a single method is used.

- Can be used to increase the generalisability of the results.

- Qualitative and quantitative research used together produce more complete knowledge necessary to inform theory and practice.

\section{Weaknesses of Mixed Method Researches}

- Sometimes difficult for a single researcher to carry out both qualitative and quantitative research especially if two or more approaches are expected to be used concurrently.

- Researcher has to learn multiple methods and approaches and understand how to mix them appropriately.

- Methodological purists contend that one should always work within either a qualitative or a quantitative paradigm.

- More expensive and time consuming.

\section{Conclusion}

Multi-method scholarship has contributed to methodological pluralism insofar as it implies that formal, quantitative, and qualitative methods represent a coherent strategy for overcoming the trade offs of different methods in research. The volume and richness of qualitative data are often highlighted, as are the distinctive approaches qualitative researchers bring to analysis and interpretation, and the kinds of output that derive from qualitative research. However, views on the modes operandi of qualitative research practice can or should be assessed depend in part on positions that people hold on key areas of philosophical debate. Since different methodological approaches are underpinned by particular philosophical or theoretical assumptions, researchers should maintain consistency between their philosophical starting point and the methods they adopt. Also, better quality work is produced if a range of approaches and methods are considered and choices made according to the aims and context of the research. Viewed in these terms, pluralistic research is not merely a pragmatic option for dealing with different elements of a research program or with practical challenges that arise in the course of research. Instead, it is emerging as a 'best practice' accompanied by the expectation that a single scholar will produce better research by using two or more methods in executing a single project. 


\section{References}

[1]. Barker, C., \& Pistrang, N. (2005). Quality Criteria under Methodological Pluralism: Implications for Conducting and Evaluating Research. American Journal of Community Psychology, 35(3/4), 201-211.

[2]. Bednarz, D. (1985). Quantity and quality in evaluation research: a divergent view. Evaluation and Program Planning, 8: 289-306.

[3]. Bhaskar, R.(1978). A Realist Theory of Science, Hassocks: Harvester Press.

[4]. Blaikie, N. (2007). Approaches to Social Inquiry, 2nd edition, Cambridge: Polity.

[5]. Bryman, A. (2007). Barriers to integrating quantitative and qualitative research. Journal of Mixed Methods Research, 1 (1), 8-22.

[6]. Bryman, Alan. (1988). Quantity and Quality in Social Research, London, Unwin Hyman.

[7]. Campbell, Donald T. \& Julian C. Stanley. (1963). Experimental and Quasi-Experimental Designs for Research. Boston: Houghton Mifflin.

[8]. Caracelli, V. J., \& Greene, J. C. (1997). Crafting mixed-method evaluation designs. In J. C. Greene, \& V. J. Caracelli (Eds), Advances in mixed-method evaluation: The challenges and benefits of integrating diverse paradigms (pp. 19-32). San Francisco: Jossey-Bass.

[9]. Cohen, L., L. Manion, et al. (2007). Research methods in education. New York: Routledge.

[10]. Cook, T. D. \& Campbell, D. T. (1979). Quasi- Experimentation: Design and Analysis for Field Settings. Rand McNally, Chicago, Illinois.

[11]. Coxon, T. (2005). Integrating Qualitative and Quantitative Data: What Does the User Need? FQS (Forum: Qualitative Social Research) 6(2). http://www.qualitativeresearch.net/fqs/fqs-eng.htm

[12]. Creswell, J. W, Plano Clark, V. L., Guttmann, M. L., \& Hanson, E. E. (2003). Advanced mixed methods research design. In A.Tashakkori and C. Teddlie (Eds.), Handbook of mixed methods in social and be-havioral research (pp. 209-240). Thousand Oaks, CA: Sage.

[13]. Creswell, J.W. (2013). Qualitative Inquiry and Research Design: Choosing among Five Approaches, 3rd edition, Thousand Oaks, CA: Sage

[14]. Crotty, M. (1998). The Foundations of Social Research: Meaning and Perspective in the Research Process. London: SAGE Publications Ltd.

[15]. Davis, J. (2009). Complementary Research Methods in Humanistic and Transpersonal Psychology: A Case for Methodological Pluralism, The Humanistic Psychologist, 37: 4-23.

[16]. Denzin, N. K. (2001). Interpretive Interactionism (Applied Social Research Methods Series). Sage Publications, London 2001

[17]. Dube \& Pre. (2003). Information Systems Positivist Case Research. Management Information

[18]. Firebaugh, G. (2008). Seven rules for social research. Princeton, NJ: Princeton University Press.

[19]. Greene, J. \& C. McClintock. (1985). Triangulation in evaluation: design and analysis issues.

[20]. Grix, J. (2004). The foundations of research. New York: Palgrave MacMillan.

[21]. Guba, E. G. (1978). Toward a methodology of naturalistic inquiry in educational evaluation. Monograph 8. Los Angeles: UCLA Center for the Study of Evaluation.

[22]. Holloway, I., \& Wheeler, S. (2010). Qualitative research in nursing. $4^{\text {th }}$ ed. Oxford: Blackwell Publishing.

[23]. Hughes, J. \& Sharrock, W. (1997). The Philosophy of Social Research, London: Routledge.

[24]. Johnson, R. B. \& A. J. Onwuegbuzie. (2004). Mixed methods research: A research paradigm whose time has come. Educational Researcher, 33 (7), 14-26.

[25]. Kember, D. \& Dekkers, J. (1987). 'The role of study centers for academic support in distance education' Distance Education 8 (1), 4-17

[26]. Lather, P. (1992). Critical Frames in Educational Research: Feminist And Post-structural Perspectives. Theory into Practice. 31 (2), $87-99$.

[27]. Lincoln, Y. S., \& Guba, E. G. (1985). Naturalistic inquiry. Beverly Hills, CA: Sage.

[28]. Madill, A., Jordan, A. \& Shirley, C. (2000). Objectivity and reliability in qualitative analysis: realist contextualist and radical constructionist epistemologies.

[29]. Maxcy, S. (2003). Pragmatic threads in mixed methods research in the social sciences: The search for multiple modes of inquiry and the end of the philosophy of formalism in Handbook of Mixed Methods in Social \& Behavioral Research, Tashakkori, A \& Teddlie, C. (Eds) 2003, Sage, California.

[30]. Mertens, D. M. (2005). Research methods in education and psychology: Integrating diversity with quantitative and qualitative approaches. ( $2^{\text {nd }}$ ed.) Thousand Oaks: Sage.

[31]. Osman, R., \& Wagner, G. A. (1987). New Zealand management students' perceptions of communication technologies in correspondence education. Distance Education, 8(1), 47-63.

[32]. Patton, M.Q. (2002). Qualitative Research and Evaluation Methods. Thousand Oaks, CA: Sage Publications

[33]. Ragin, Charles C. (1994). Constructing Social Research: The Unity and Diversity of Method. Pine Forge Press.

[34]. Shih, F. J. (1998). Triangulation in nursing research: Issues of conceptual clarity and purpose. Journal of Advanced Nursing, 28(3), 631-641.

[35]. Silverman, D. (1993). Interpreting Qualitati ve Data. Thousand Oaks, CA: Sage.

[36]. Smith, R. B., \& Manning, P. K. (1982). Qualitative methods: Volume II of handbook of social science methods. Cambridge, MA : Ballinger

[37]. Tashakkori, Abbas, \& Charles Teddlie, eds. (2003). Handbook of Mixed-Method Social and Behavioral Research. Thousand Oaks, CA: Sage Publications.

[38]. Todd, J., Green, G., Harrison, M., et al .(2004). Social exclusion in clients with comorbid mental health and substance misuse problems. Social Psychiatry and Psychiatric Epidemiology, 39, $581-587$.

[39]. Willis, J.W. (2007) Foundations of Qualitative Reseasrch, Thousand Oaks, CA: Sage. 